\title{
Sinuosity of Atmospheric Circulation over Southeastern China and Its Relationship to Surface Air Temperature and High Temperature Extremes
}

\author{
Yongdi Wang ${ }^{1, *(\mathbb{D}}$, Fei Wang ${ }^{2}$ and Xinyu Sun ${ }^{3}$ \\ 1 School of Remote Sensing and Geomatics Engineering, Nanjing University of Information Science and \\ Technology, Nanjing 210044, China \\ 2 Key Laboratory of Radar Imaging and Microwave Photonics, Nanjing University of Aeronautics and \\ Astronautics, Ministry of Education, Nanjing 210016, China; wangxiaoxian@nuaa.edu.cn \\ 3 Key Laboratory of Meteorological Disaster, Ministry of Education (KLME), Joint International Research \\ Laboratory of Climate and Environment Change (ILCEC), Collaborative Innovation Center on Forecast and \\ Evaluation of Meteorological Disasters (CIC-FEMD), Jiangsu Key Laboratory of Meteorological Observation \\ and Information Processing, Jiangsu Technology \& Engineering Center of Meteorological Sensor \\ Network/School of Electronic \& Information Engineering, Nanjing University of Information Science and \\ Technology, Nanjing 210044, China; sxy@nuist.edu.cn \\ * Correspondence: ydwang@nuist.edu.cn
}

check for updates

Citation: Wang, Y.; Wang, F.; Sun, X. Sinuosity of Atmospheric Circulation over Southeastern China and Its Relationship to Surface Air Temperature and High Temperature Extremes. Atmosphere 2021, 12, 1139. https: / / doi.org/10.3390/ atmos12091139

Academic Editors: Liang Ning, Jun Cheng, Zhengguo Shi, Mi Yan, Yonggang Liu, Zhengyu Liu,

Ruibo Zhang, Deepak Chandan and John W. Williams

\section{Received: 5 July 2021}

Accepted: 1 September 2021

Published: 4 September 2021

Publisher's Note: MDPI stays neutral with regard to jurisdictional claims in published maps and institutional affiliations.

Copyright: (c) 2021 by the authors. Licensee MDPI, Basel, Switzerland. This article is an open access article distributed under the terms and conditions of the Creative Commons Attribution (CC BY) license (https:// creativecommons.org/licenses/by/ $4.0 /)$.

\begin{abstract}
Linking sinuosity, a fairly recently developed metric, with high temperature extremes (HTEs) can be both useful and insightful to better understand the physical mechanisms behind HTEs. However, it is not clear whether there exists a relationship between the sinuosity changes and HTE changes in present and future climate conditions over southeastern China. In this paper, the anomalous characteristics of the atmospheric circulation are quantified by sinuosity. Three sinuosity metrics are used in this study: individual sinuosity (SIN), aggregate sinuosity (ASIN), and comprehensive sinuosity (CSIN). Furthermore, we examine the relationship between sinuosity changes and HTE changes in present and future climate conditions. ASIN is strongly correlated with surface air temperature (SAT). We find that the influence of individual sinuosity (SIN) at different latitudes on the SAT of southeastern China is different. The SIN of low (middle) latitude isohypses has significant positive (negative) correlations with the SAT of southeastern China. The SIN of high-latitude isohypses is rather limited and can therefore be ignored. The projected relationship between the sinuosity changes and HTE changes in the late 21st century suggests similar results. The change in SAT is related to the changes in climate variables over southeastern China in the future, and these changes increase with the increase in Z500 or V850 and the decrease in U500. Moreover, the frequencies of large (small) comprehensive sinuosity (CSIN) values at low (mid) latitudes will increase. At the end of the 21st century, Z500 isohypses at different latitudes will have an obvious poleward shift. Our results indicate that measuring the aggregate waviness of the midtropospheric flow (via sinuosity) can provide insight regarding HTEs, and the climate model output can be used to examine the future likelihood of increased HTE.
\end{abstract}

Keywords: sinuosity; atmospheric circulation; southeastern China; high temperature extremes

\section{Introduction}

The probability of high temperature extreme (hereafter HTE) occurrences is ever increasing over many parts of the world. In line with the intensifying global warming, the intensities and durations of HTEs have also increased [1-5]. It is expected that this warming trend will continue in the 21st century [6-9]. Southeastern China is one of the most vulnerable regions, and it plays a decisive role from societal and economic points of view. It is of great scientific and practical significance to analyze and study the characteristics and 
formation mechanism of HTEs in southeastern China, whether to understand the climate characteristics in this area or to predict HTEs in the future.

Previous studies have shown that anticyclonic anomalies are among the causes of high temperatures and high pressures in various regions (e.g., [1,10-12]). On the one hand, the subsidence associated with anticyclonic anomalies can increase air temperature through adiabatic heating. On the other hand, clouds can be reduced, and solar radiation on the earth's surface is enhanced [13-17]. Many factors affect surface air temperature (SAT) change. In addition to vertical flows, horizontal flows also affect SAT through temperature advection $[18,19]$. Overlying geopotential height anomaly at middle to upper levels and temperature advection by the meridional wind at lower levels are the two most important circulation factors affecting SAT [20-22]. The factors that cause HTEs in China are significantly different in the southern and northern regions. In the north of China, HTEs occur frequently when the geopotential height is high. Different from the north, the HTEs over the central and southern regions of China are related to not only geopotential height anomalies but also the advection of cold and warm air in the lower level. Therefore, it is important to analyze not only SAT but also the variables closely related to SAT in order to comprehensively understand the internal physical mechanisms that play dominant roles [21].

Sinuosity, a metric used to characterize the sinuosity of the isohypse of $500 \mathrm{hPa}$ geopotential height (representing the isohypse departure from a purely zonal orientation of $500 \mathrm{hPa}$ geopotential height), is defined as the ratio of the curvilinear length of a $500 \mathrm{hPa}$ geopotential height isohypse to the perimeter of its equivalent latitude $[23,24]$. The isohypse and equivalent latitude enclose the same area within the regional boundaries. Using the sinuosity metric, atmospheric waviness can be quantified, and closed circulation systems (such as blocking highs and cutoff lows) can also be considered. The sinuosity metric has previously been shown to be a useful tool [23-26], although it has not yet been applied to southeastern China.

Because China has a vast territory and complex terrain, there are likely significant spatial differences in the distribution of the general atmospheric circulation responsible for the occurrence of HTEs. In addition, the physical mechanisms and related effects are very different between regions [27]. In consideration of HTEs having obvious regional characteristics in the specific change process and amplitude, the local character of the southeastern China region should be considered in this study. Moreover, in view of the distribution and seasonal movement of the pressure belt and wind belt, maybe the impacts of circulation at different latitudes on southeastern China also differ.

In the future, atmospheric dynamics will be expected to be affected by the latitudinal expansion of the tropics under the effect of global warming [28]. The position and intensity of westerlies will all be changed. Through this study, we seek to answer the following questions: (1) Can the sinuosity metric quantify the anomalous characteristics of atmospheric circulation? (2) Does there exist a relationship between SAT changes and sinuosity changes in the future? (3) Are future changes in SAT due to bending changes of SIN or due to the northward movement of the pressure belts and wind belts?

A set of sinuosity metrics is used in this study to evaluate whether the anomalous characteristics of atmospheric circulation can be quantified efficiently. The first objective of this study is to examine whether the sinuosity metrics can be used to quantify waviness and to examine whether there is a significant correlation between sinuosity and climate variables. The second objective of this study is to simulate the future change in SAT under very strong greenhouse forcing and to analyze the relationship between sinuosity changes and SAT changes. The third objective of this study is to investigate whether the northward movements of the air pressure belts and the wind belts the fundamental cause of SIN changes and SAT changes. This manuscript is organized as follows: The data and analysis methods used in this study are described in the next two sections (Sections 2 and 3). The major results are presented in Section 4 . Section 5 provides the summary and discusses the results. 


\section{Data}

The reanalysis data are from the National Centers for Environmental Prediction/National Center for Atmospheric Research (NCEP/NCAR), which provided NCEP-DOE reanalysis II (NCEP 2) [29], which is available from 1979 to the present. We assume that the NCEP 2 reanalysis $\left(2.5^{\circ} \times 2.5^{\circ}\right)$ is a reasonable representation of the observed record for our intended impact study because it uses an updated forecast model, updated data assimilation system, improved diagnostic outputs, and fixes for the known processing problems of the NCEP-NCAR reanalysis [29].

August was chosen for the analysis because HTEs in southeastern China are most likely to appear in August, and the analysis will be representative. In this study, daily gridded data of geopotential height at $500 \mathrm{hPa}(\mathrm{Z} 500)$, the $\mathrm{u}$ component of the wind at $500 \mathrm{hPa}$ (U500), and the v component of the wind at $850 \mathrm{hPa}$ (V850) for August during 1979-2016 were used. The purpose of selecting these variables was to analyze and determine the important circulation factors affecting SAT. In addition to the dataset above, gridded daily mean SAT was obtained from a set of observed data, referred to as CN05 [30], which was available at $0.5^{\circ} \times 0.5^{\circ}$ daily resolution over China from 1961 to 2005 and provided a long-term consistent dataset.

To assess how SAT will change at the end of the 21st century, a state-of-the-art global model was selected from the Coupled Model Intercomparison Project Phase 5 (CMIP5; [31]). The simulated atmospheric data from both historical and projected (Representative Concentration Pathways 8.5 (RCP8.5)) simulations are from the Beijing Climate Center Climate System Model version 1.1 with a moderate resolution (bcc-csm1-1-m), which produces realistic climatologies in the CMIP5 suite of Chinese models [32,33]. The resolution of model bcc-csm1-1-m is $1.125^{\circ} \times 1.125^{\circ}$ (archived by the PCMDI at http:/ / pcmdi9.1lnl.gov/esgf-web-fe/: accessed on 3 September 2012). To facilitate the analysis of future changes, all the climate fields (SAT, Z500, U500, and V850) mentioned above were also calculated accordingly using bcc-csm1-1-m model data. Two 20-year time windows (1981-2000 and 2081-2100) were chosen, and we extracted bcc-csm1-1-m model data from the corresponding two periods.

\section{Methods}

\subsection{Analysis Domains}

We chose the research area in southeastern China for three reasons. First, southeastern China is highly urbanized [34-36]. Second, the area is mainly a plain area [37], so it is not necessary to consider the foehn effect caused by topographic fluctuations. Third, this area is significantly affected by monsoons [38-40], so the meridional wind should be considered in the analysis of this paper.

We performed this analysis on two spatial domains: a "small" domain $\left(25^{\circ}-35^{\circ} \mathrm{N}\right.$, $110^{\circ}-120^{\circ} \mathrm{E}$ ) in southeastern China that occupies the mid- or low-latitude location and a "large" domain $\left(0^{\circ}-90^{\circ} \mathrm{N}, 100^{\circ}-130^{\circ} \mathrm{E}\right)$, a narrow rectangle from the Equator to the North Pole that covers all of southeastern China and all different latitudes. In order to extract reasonable circulation information, the sinuosity metrics were all calculated in the large domain. Suitable isohypses were selected according to a specific location. The small domain was only used to calculate the regional mean of the climate fields. We calculated the sinuosity metrics by using Z500. SAT, U500, and V850 were used for an in-depth analysis of such aspects as the generation mechanism.

\subsection{Metrics}

\subsubsection{Individual Sinuosity (SIN)}

To express the circulation state within a latitude interval, we followed the methodology of [23] and created the individual sinuosity (SIN) that characterizes waviness in the study area. There are two kinds of isohypses: closed and nonclosed. For global problems, as shown in Figure 1a, the ratio of the perimeter can be directly calculated because of closed graphics. In more cases, we will only study the situation in a certain region so that 
isohypses will not be closed (Figure 1b). We can calculate the ratio between the length of the curve and the length of the line. In this specific operation, there are different situations, for example, those shown in Figure 1c. There are a number of contour lines at the same height. If there are several identical isohypses at the same height, the ratio of the sum of the lengths of the isohypses to the sum of the equivalent lengths of the isohypses is taken as the SIN result of those isohypses.
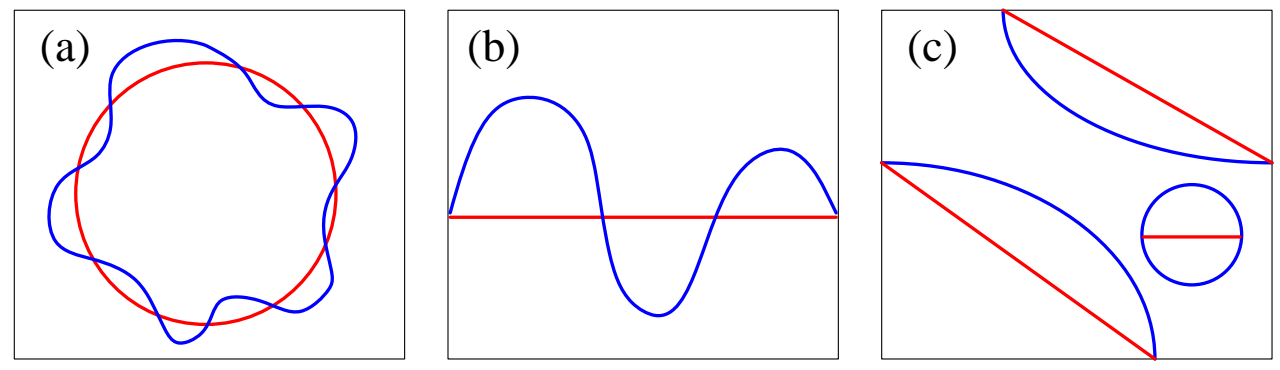

Figure 1. Example of sinuosity calculations for simple hemispheric and complex regional cases. The three different situations that are generally encountered are: (a) when the latitudes are closed within the whole northern hemisphere; (b) when the latitudes are not closed within a local area; and (c) when there is more than one contour line of the same numerical size in a region. The blue lines in the figures indicates a geopotential height contour at $500 \mathrm{hPa}$, and the red lines indicates the latitude.

\subsubsection{Aggregate Sinuosity (ASIN)}

We calculated aggregate sinuosity (ASIN) as a ratio of the sum of the isohypse lengths divided by their equivalent latitude lengths. For example, if there are five $500 \mathrm{hPa}$ isohypses $(5760,5640,5520,5400$, and $5280 \mathrm{~m})$, the ASIN metrics can be expressed as

$$
A S I N=\frac{\left[L_{5760}+L_{5760}+L_{5760}+L_{5760}+L_{5760}\right]}{\left[E L_{5760}+E L_{5760}+E L_{5760}+E L_{5760}+E L_{5760}\right]^{\prime}}
$$

where $L$ and $E L$ represent the lengths and the equivalent lengths of the isohypses within the study domain, respectively. In this specific calculation, a reasonable contour line will be selected according to its location. In this way, the circulation state within a latitude interval can be expressed by boiling down the entire regional circulation into a single metric. In this study, we selected corresponding isohypses according to different latitudes and calculated the metric according to the above formula.

\subsubsection{Comprehensive Sinuosity (CSIN)}

The comprehensive sinuosity (CSIN) metric follows that of Vavrus et al. [24]. CSIN can obtain more information on the spatial variations of waviness within the domain by expressing SIN as a function of latitude. The CSIN metric offers several advantages over SIN and ASIN, for example, in expressing SIN as a function of latitude accounts for the confounding effect of inflating geopotential heights in a warming climate [41], and identifies potentially different subregional changes in the magnitude of SIN [24].

Briefly, the CSIN metric proceeds as follows: (1) obtain a quasi-continuous magnitude of sinuosity across a span of geopotential height characteristics of the extratropics, (2) compute the zonally averaged geopotential height across each latitude band on every day, (3) assign to each latitude the SIN corresponding to the height contour representing that latitude. Further details about the procedure for the CSIN metric can be found in Vavrus et al. [24]. 


\section{Results and Analysis}

\subsection{Quantification of Anomalous Circulation States Using ASIN}

\subsubsection{Correlation between ASIN and Climate Variables}

In order to have an outline understanding of ASIN as a whole, we calculated the probability density function (PDF) of the ASIN metric in the "large" domain. There are 13 isohypses (varied from 5350 to $5950 \mathrm{~m}$ in steps of $50 \mathrm{~m}$ ) of geopotential height of $500 \mathrm{hPa}$ in the calculation formula of ASIN. For the other variables (SAT, Z500, U500, and V850), a spatial mean over the whole domain was also considered. All variables were computed in January and the whole year (Annual) in order to compare with the results in August.

PDF results were plotted in Figure 2. The three curves in each subgraph represent the PDF of Annual (black), January (blue), and August (red), respectively. The values of variables in August were often larger than those in January, except for U500. This suggests that greater westerly winds in winter will bring cold air and lead to lower temperatures. Additionally, the westerly wind in summer becomes weaker, which is conducive to the accumulation of heat and leads to the rise of temperature.

(a) ASIN
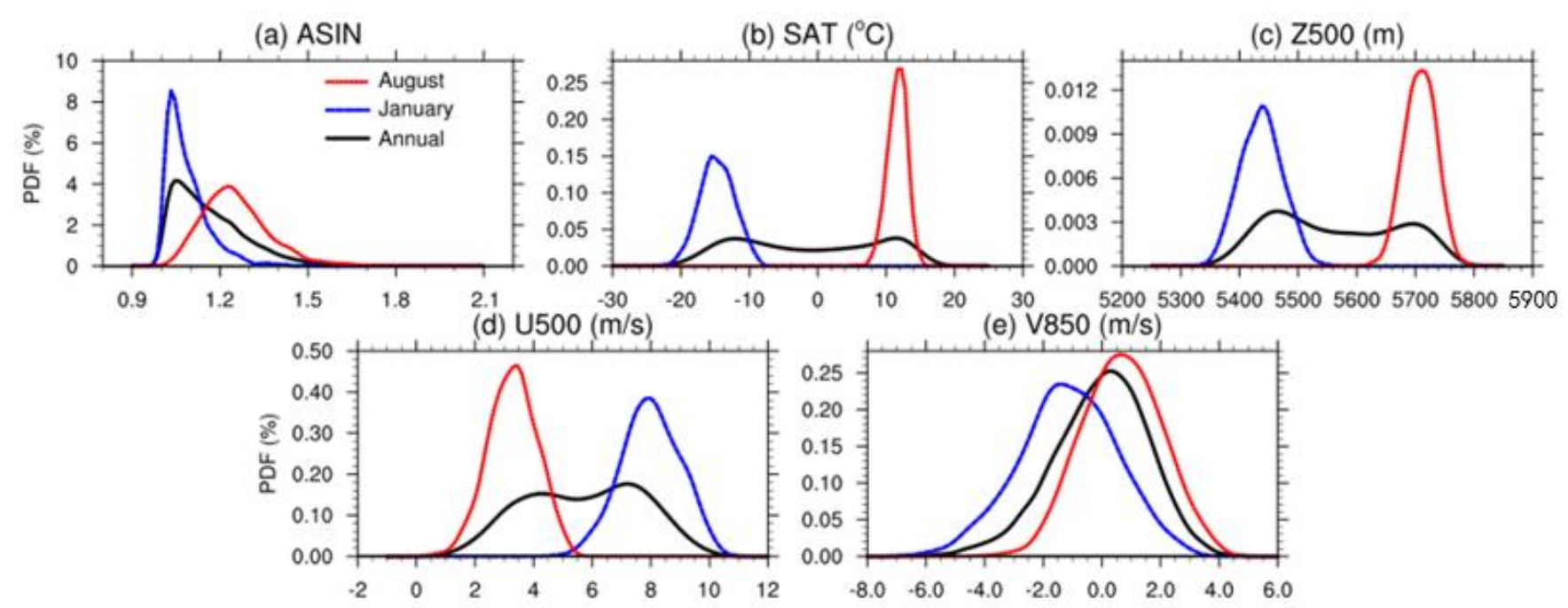

(e) $\mathrm{V} 850(\mathrm{~m} / \mathrm{s})$

Figure 2. Probability density functions (PDFs) of (a) ASIN, (b) SAT $\left({ }^{\circ} \mathrm{C}\right)$, (c) Z500 (m), (d) U500 (m/s), and (e) V850 (m/s) in the "large" domain. The three curves in each subgraph represent Annual (black), January (blue), and August (red).

If there exists a strong correlation between ASIN and climate variables, it would help us to analyze the possible causes of HTEs in depth. For that purpose, we calculated the correlations between ASIN and the regional average of climatic variables in the large domain, adopting three different means of calculation: (a) daily variation, (b) climatic mean, and (c) interannual variability. The results are presented in Table 1.

Table 1. Correlation coefficients $r$ between ASIN and SAT $\left({ }^{\circ} \mathrm{C}\right), \mathrm{Z} 500(\mathrm{~m}), \mathrm{U} 500$ (m/s), and V850 (m/s) in August. The bold font marks the correlations as being significant (at the $95 \%$ confidence level).

\begin{tabular}{cccc}
\hline Climate Variable & Daily Variation & Climatological Mean & Interannual Variability \\
\hline SAT & 0.24 & 0.75 & 0.41 \\
Z500 & 0.35 & 0.71 & $\mathbf{0 . 5 8}$ \\
U500 & -0.24 & -0.78 & -0.51 \\
V850 & $\mathbf{0 . 1 2}$ & $\mathbf{0 . 4 3}$ & 0.23 \\
\hline
\end{tabular}

Correlating ASIN and the different variables, we found significantly positive correlations (at the 95\% confidence level) between ASIN and SAT $(0.24,0.75$, and 0.41$)$ and between ASIN and Z500 $(0.35,0.71$, and 0.58$)$ for all the calculation means. In contrast, the relationship between ASIN and U500 ( $-0.24,-0.78$, and -0.51$)$ was significantly negative 
(at the $95 \%$ confidence level) by all the means. The correlation coefficient between ASIN and V850 was 0.12 based on daily variation and 0.43 based on climatic mean (at the $95 \%$ confidence level). In contrast, the relationship between ASIN and V850 based on interannual variability was weaker $(r=0.23)$. These results suggest that ASIN can quantify exceptional circulation states effectively.

\subsubsection{Different Circulation States in August}

Having analyzed the correlations between ASIN and different variables for the large domain, the next step is to understand the laws of different circulation states corresponding to different metric values in August. Figure 3a,b shows the states of Z500 corresponding to the highest and lowest ASIN in August. A very zonally oriented flow with an ASIN of 1.03 occurred on 10 August 2003 (Figure 3a). In this case, the isohypses on the map are straight, meaning that HTEs are difficult to achieve when ASIN reaches its lowest level. In contrast, the remarkably muddled circulation pattern on 06 August 2002 yielded a record-high ASIN of 1.79 (Figure $3 \mathrm{~b}$ ). In this case, isohypses are distorted, the zonal wind is restricted, and heat is easily accumulated. This means that HTEs are more likely to occur when ASIN reaches its peak.

\section{(a) $\mathrm{ASIN}=1.03$}

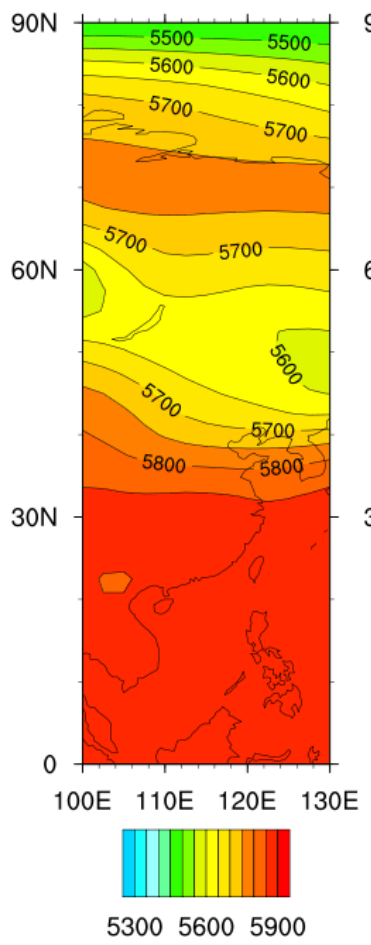

(b) $\mathrm{ASIN}=1.79$

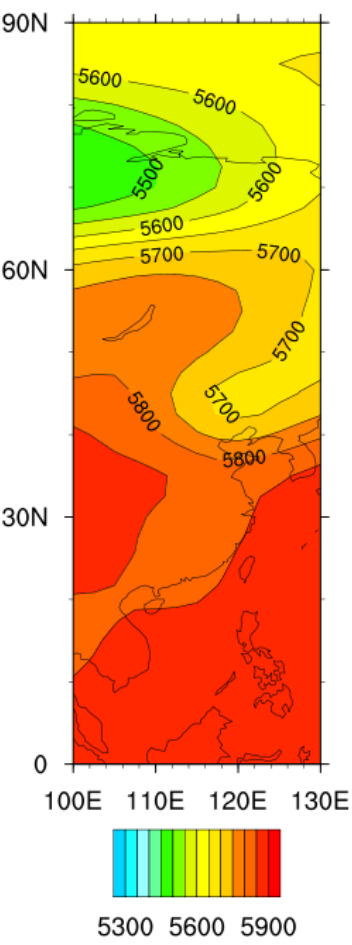

(c) ASIN $<P \_05$ th

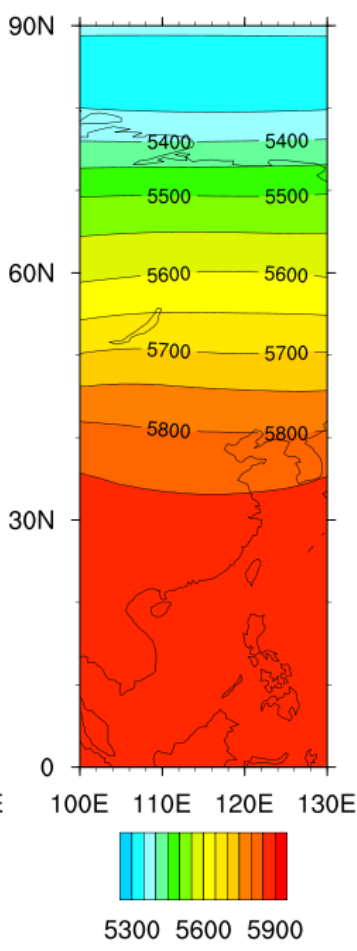

(d) ASIN>P_95th

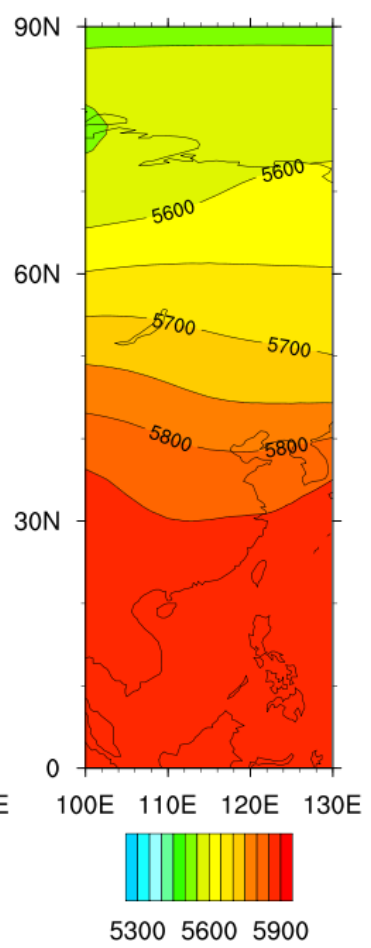

Figure 3. Different circulation states corresponding to different ASIN values in August, illustrated at Z500 (m). (a) Lowest (ASIN = 1.03), (b) highest (ASIN = 1.79), (c) mean of the 5\% lowest ASIN days (ASIN < P_05th), (d) mean of the 5\% highest ASIN days (ASIN > P_95th).

Choosing two single days does not lead to robust conclusions. It would be more convincing if the composite of the $5 \%$ highest and $5 \%$ lowest ASIN days would be considered. Figure $3 \mathrm{c}$, d shows the mean of the $5 \%$ lowest ASIN days (ASIN $<$ P_05th) and the mean of the $5 \%$ highest ASIN days (ASIN > P_95th). During the 5\% lowest ASIN days (ASIN $<$ P_05th), isohypses are more straight (Figure 3c). During the $5 \%$ highest ASIN days (ASIN > P_95th), isohypses are more bending (Figure 3d). This result further confirms the previous conclusion that HTEs are more likely to occur when ASIN is in the $5 \%$ highest ASIN days. 


\subsubsection{Sensitivity Testing of the Choice of Different Size Areas}

To quantify how sensitive our analysis is to the choice of area sizes, we calculated the correlation coefficients between ASIN and SAT, adopting three different means of calculation (daily variation, climatic mean, and interannual variability) for four different size areas: $10^{\circ} \times 10^{\circ}\left(25^{\circ}-35^{\circ} \mathrm{N}, 110^{\circ}-120^{\circ} \mathrm{E}\right), 20^{\circ} \times 20^{\circ}\left(20^{\circ}-40^{\circ} \mathrm{N}, 105^{\circ}-125^{\circ} \mathrm{E}\right), 30^{\circ} \times 30^{\circ}$ $\left(15^{\circ}-45^{\circ} \mathrm{N}, 100^{\circ}-130^{\circ} \mathrm{E}\right)$, and $40^{\circ} \times 40^{\circ}\left(10^{\circ}-50^{\circ} \mathrm{N}, 95^{\circ}-135^{\circ} \mathrm{E}\right)$.

We found significantly positive correlations (at the $95 \%$ confidence level) occurring over all domains and all means of calculation. For daily variation, the calculation results were $0.24,0.17,0.18$, and 0.18 , respectively. For climatic mean, the calculation results were $0.75,0.77,0.76$, and 0.76 respectively. For interannual variability, the calculation results were $0.41,0.35,0.35$, and 0.31 respectively. The calculation results all showed a significant correlation (at the $95 \%$ confidence level). We can conclude that the sensitivity of the choice of area sizes is small enough for the analysis in this paper.

\subsection{Influence of Sinuosity at Different Latitudes on SAT in Southeastern China 4.2.1. SIN}

Southeastern China is the most significant area of the East Asian summer monsoon. The average value of each variable in a large area failed to reflect the particularity of the regional area (Section 4.1). We are more concerned about whether the method is also applicable to that region. Therefore, we narrowed the study area to the small domain. To investigate the effect of different isohypses on the small-domain SAT, the individual sinuosity (SIN) of different latitudes was used for calculation and analysis. We calculated the correlation coefficients between the SIN of the 13 isohypses $(5950-5350 \mathrm{~m})$ and the SAT of the small domain, respectively. The results are shown in Table 2. The significant correlations (at the 95\% confidence level) are shown in boldface.

Table 2. Analysis of individual sinuosity (SIN) and SAT $\left({ }^{\circ} \mathrm{C}\right)$ correlation coefficients of the 13 isohypses from 5950 to $5350 \mathrm{~m}$ of Z500. Bold font marks the correlations as significant (at the $95 \%$ confidence level).

\begin{tabular}{cccccccccccccc}
\hline Isohypse & $\mathbf{5 9 5 0}$ & $\mathbf{5 9 0 0}$ & $\mathbf{5 8 5 0}$ & $\mathbf{5 8 0 0}$ & $\mathbf{5 7 5 0}$ & $\mathbf{5 7 0 0}$ & $\mathbf{5 6 5 0}$ & $\mathbf{5 6 0 0}$ & $\mathbf{5 5 5 0}$ & $\mathbf{5 5 0 0}$ & $\mathbf{5 4 5 0}$ & $\mathbf{5 4 0 0}$ & $\mathbf{5 3 5 0}$ \\
\hline r values & 0.01 & $\mathbf{0 . 2 0}$ & 0.04 & $\mathbf{- 0 . 2 1}$ & $\mathbf{- 0 . 1 3}$ & -0.02 & 0.02 & 0.15 & 0.11 & 0.03 & -0.07 & -0.07 & -0.05 \\
\hline
\end{tabular}

The correlations vary widely from one isohypse to another, ranging from positive to negative. There are two negative correlation positions: one is between 5800 and $5700 \mathrm{~m}$, and the other is between 5450 and $5350 \mathrm{~m}$. A highly positive correlation between the SIN and the SAT of the small domain suggests that the SAT will rise (decrease) with the increase (decrease) in the SIN of the isohypse (such as $5900 \mathrm{~m}$ ). In contrast, a very negative correlation here means that the SAT will rise (decrease) with the decrease (increase) in the SIN of the isohypse (such as $5800 \mathrm{~m}$ ). The above results show that the SIN of different isohypses have different effects on the SAT in southeastern China. It is well known from dynamic relationships that SAT is not a linear function of the baric gradients in the mid atmosphere. The presence of the turbulent boundary layer in the low troposphere is characterized by the complex variability of the vertical turbulent coefficient. It causes the complex (nonlinear) relationship between baric fields and SAT.

Observing the average location of each isohypse (not shown in the figure), we can find that the values of the isohypses are arranged unevenly from high to low from the Equator to the North Pole. In particular, the proportion of the part above $5800 \mathrm{~m}$ is approximately one-third of the total area. Comparing the distribution of U500, we found that $30^{\circ} \mathrm{N}$ latitude is an obvious dividing line of U500 (not shown in the figure). U500 is negative (positive) to the south (north) of that line. In particular, at $40^{\circ}-45^{\circ} \mathrm{N}$, U500 reached the highest value $(8 \mathrm{~m} / \mathrm{s})$. 


\subsubsection{ASIN}

To understand the influence of ASIN at different latitudes on the SAT of the small domain, three groups of isohypses (from minimum value to maximum value in steps of $10 \mathrm{~m}$ ) were selected in three regions: low latitude $(5850-5900 \mathrm{~m})$, middle latitude (5750-5800 m), and high latitude (5400-5450 m). The average SATs corresponding to different percentiles of ASIN were calculated (Figure 4a-c). As illustrated in Figure 4, the SAT in the small domain will increase with the increase in ASIN at low latitudes but will decrease with the increase in ASIN at middle or high latitudes.

(a) Low Lat

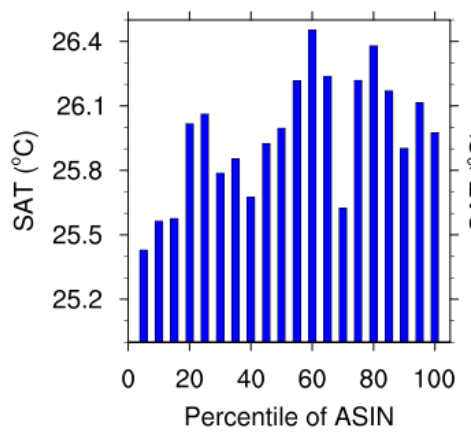

(b) Middle Lat

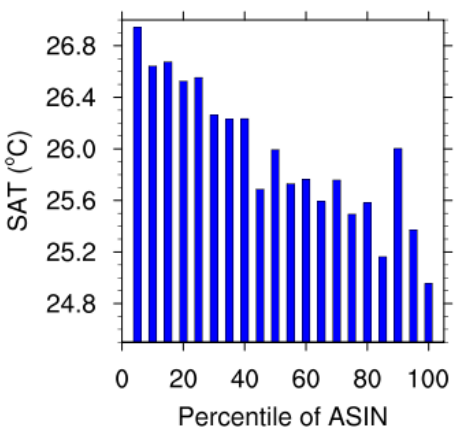

(c) High Lat



Figure 4. The influence of ASIN at different latitudes-(a) low latitude (5850-5900 m), (b) middle latitude (5750-5800 m), (c) high latitude (5400-5450 m)—on the SAT $\left({ }^{\circ} \mathrm{C}\right)$ in southeastern China.

These results suggest that the influence of the ASIN of isohypses at low latitudes (Figure 4a) is obvious in the small domain. The larger the ASIN is, the more likely it is to block the propagation of U500. It is attributed to the ASIN of these isohypses that cover southeastern China. Thus, heat can be easily accumulated, and HTEs can be easily formed. The ASIN of isohypses in the middle latitudes (Figure $4 \mathrm{~b}$ ) plays a role in the isolation zone, and its effect on the SAT in the small region is also obvious. The zonal wind is generally strong from the west and can block cold air going south. When the west winds are strong in the high latitudes (Figure 4c), the cold air in the area cannot easily move south and affects the SAT in the middle and low latitudes.

\subsection{Future Changes of Climate Variables in Southeastern China}

\subsubsection{Changes of SATs}

Figure $5 \mathrm{a}, \mathrm{b}$ shows the mean SAT of southeastern China at the end of the 20th century and the end of the 21st century, respectively. Additionally, Figure $5 c$ shows the difference between the two periods.

(a) SAT $\left(20^{\text {th }}\right){ }^{\circ} \mathrm{C}$

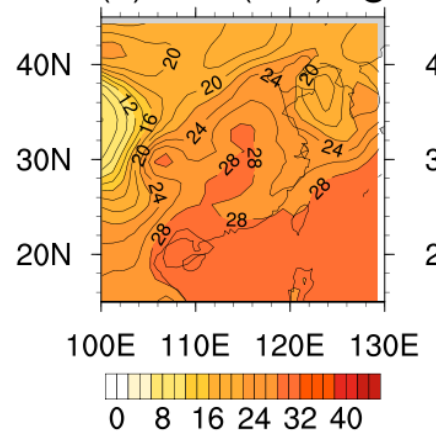

(b) SAT $\left(21^{\text {st }}\right){ }^{\circ} \mathrm{C}$

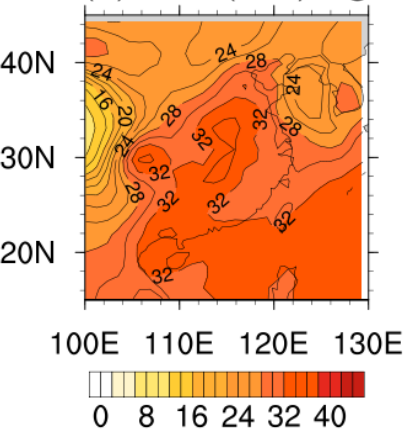

(c) SAT (Diff) ${ }^{\circ} \mathrm{C}$

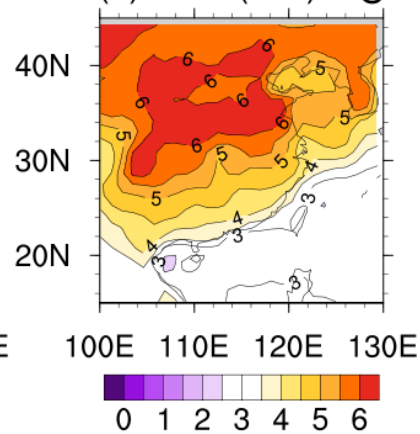

Figure 5. SAT $\left({ }^{\circ} \mathrm{C}\right)$ changes in southeastern China at the end of the 21st century under future scenarios (Representative Concentration Pathways 8.5 (RCP8.5)): (a) late 20th century, (b) late 21st century, (c) difference between the two periods. 
Projected SAT changes in southeastern China show a regional warming with respect to the present climate. Viewing the SAT across southeastern China, we find that the lower (higher) the SAT was, the larger (smaller) the change was. Projections of the mean SAT indicate a northwest-southeast gradient warming in August over southeastern China. On the whole, SAT changes are very uneven. Our findings are consistent with previous studies that pointed out the RCP8.5 scenario with the greatest global mean temperature increase [42]. Further analysis is needed regarding what reason leads to its inhomogeneous changes.

\subsubsection{Relationship between Wind, Pressure, and Temperature}

To analyze the possible causes of SAT changes in depth, the relationships between SAT and several climate variables were calculated in the small domain (Figure 6). On the field of geopotential height (Figure 6a), we find that SAT will increase with the increase in Z500. On the wind field (Figure 6b), we find that SAT will decrease with the increase in U500. Therefore, there is a significant negative correlation between SAT and zonal wind. In contrast, SAT increases with the increase in V850 (Figure 6c), which shows that SAT has a significant positive correlation with the meridional wind (V850) in the local troposphere.

(a) Z500

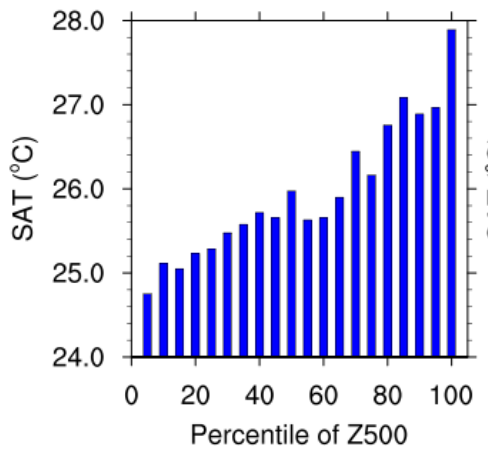

(b) U500

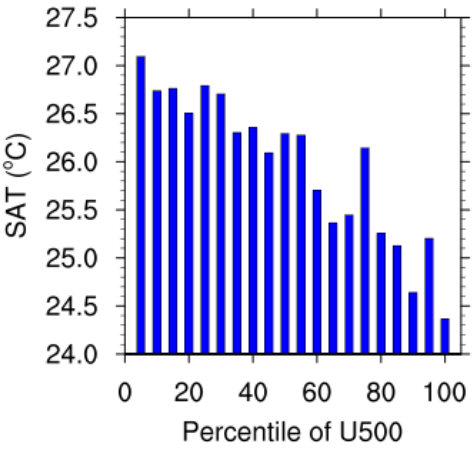

(c) V850

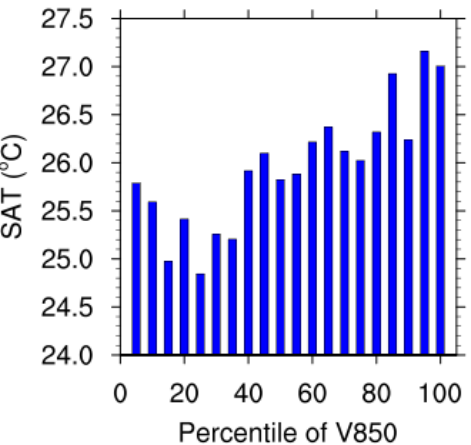

Figure 6. Relationship between SAT $\left({ }^{\circ} \mathrm{C}\right)$ and climate variables: (a) Z500 (m), (b) U500 (m/s), (c) V850 (m/s).

\subsubsection{Changes in Wind and Pressure}

Figure 7 shows the histograms of daily August Z500, U500, and V850 in the late 20th century and the late 21st century. We find that the histogram of Z500 has shifted significantly to the right. U500 will decrease. That is, the frequency of westerly winds will decrease, and the frequency of easterly winds will increase. In contrast, V850 will become larger. In other words, the frequency of north winds will decrease, and the frequency of south winds will rise. All of these changes are very conducive to the formation of HTEs.

(a) Z500

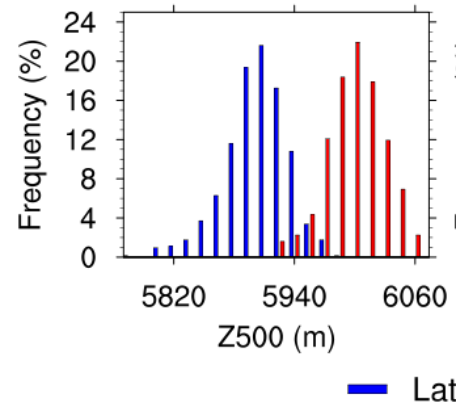

(b) U500

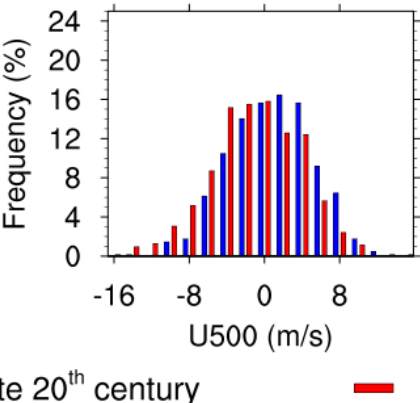

(c) V850

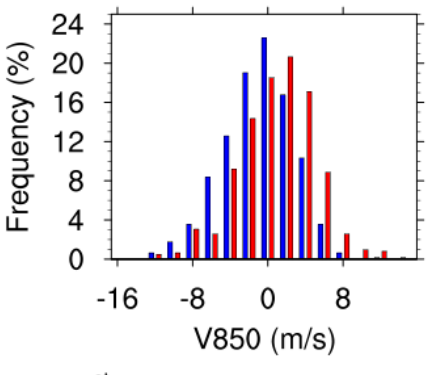

Late $21^{\text {st }}$ century

Figure 7. Changes to several climatic variables in southeastern China under the future scenario: (a) Z500 (m), (b) U500 (m/s), (c) $\operatorname{V850}(\mathrm{m} / \mathrm{s})$. 


\subsection{Distribution Regularities in Different Latitudes for Each Climate Variable}

To determine whether the change in SAT in the small domain depends on the changes of other climatic variables in that domain or is influenced by a wider range, isohypses were expanded to the North Pole at the end of the 21st century (Figure 8). Higher isohypses will move poleward and replace the lower ones. Isohypses near the North Pole will continue to retreat until they disappear. For example, those at $5950 \mathrm{~m}$ will be replaced by those at $6050 \mathrm{~m}$, and those at $5400 \mathrm{~m}$ and below will disappear.

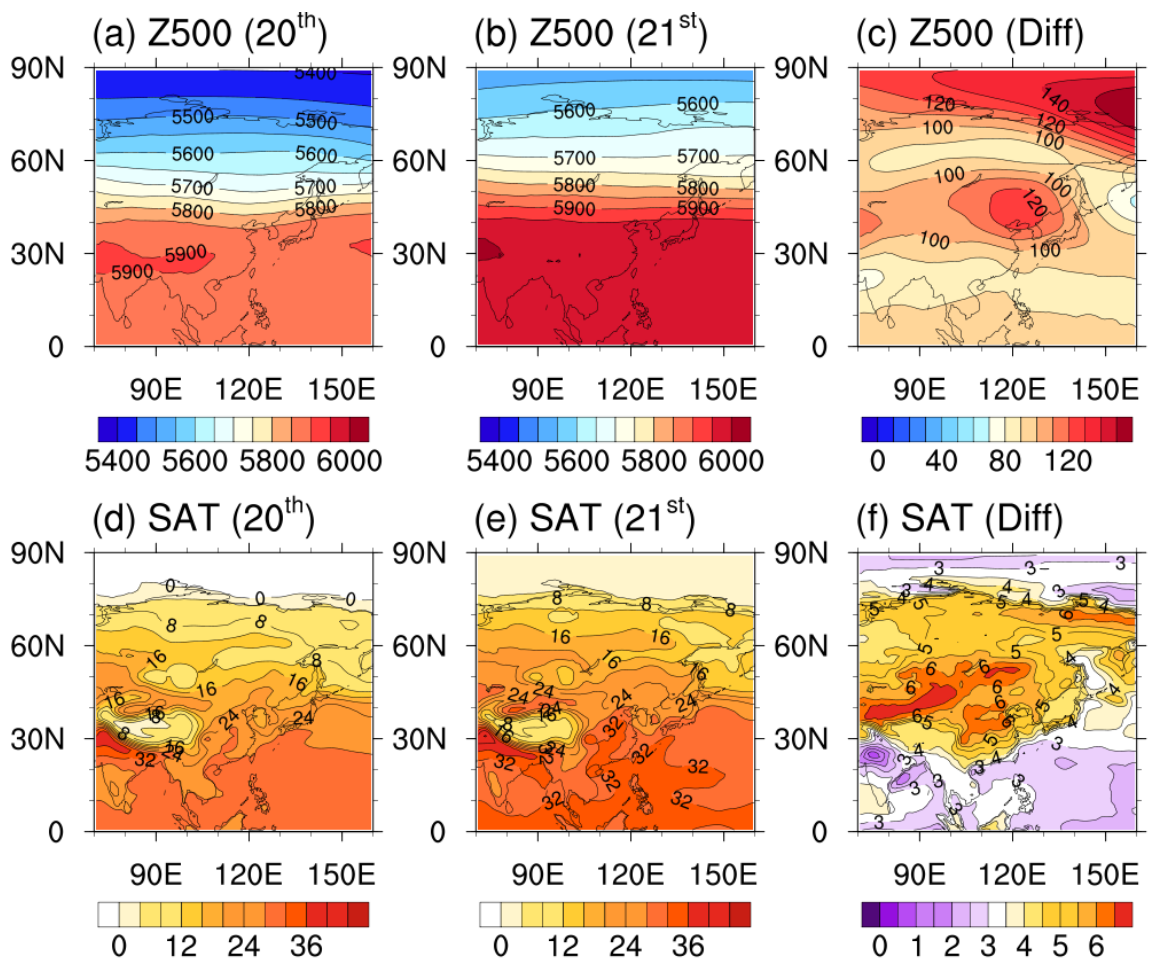

Figure 8. Z500 (m) and SAT $\left({ }^{\circ} \mathrm{C}\right)$ changes in the first row and the differences between the two periods are shown in the second row: $(\mathbf{a}, \mathbf{d})$ late 20th century, $(\mathbf{b}, \mathbf{e})$ late 21 st century, $(\mathbf{c}, \mathbf{f})$ difference between the two periods.

By observation and analysis, it can be found that there is a very regular distribution of isohypses from the Equator to the North Pole. The distribution of SAT also shows a certain gradient (but not very regular) from low latitudes to high latitudes (Figure 8d,e). What needs special attention is that the place with the greatest change in SAT is in the middle latitudes (Figure 8f).

To more clearly see the distribution of the other climate variables at different latitudes, we plot the averages for each variable at the different longitudes in Figure 9. The first row shows the states of the 20th century (blue line) and the 21st century (red line). The differences between the two periods are shown in the second row, which can be divided into four belts, which are described as follows.

\subsection{1. $50^{\circ} \mathrm{N}-60^{\circ} \mathrm{N}$}

In this interval, U500 is the area where the westerly wind increases the most, and the latitude belt acts as a barrier. In the future, it will still block the cold air coming from the high latitudes. With the northward movement of U500, the lower the latitude is, the higher the SAT is in this interval. The change in Z500 is also similar to the SAT change. The change in V850 is almost zero, and it will not change. 
(a) SAT

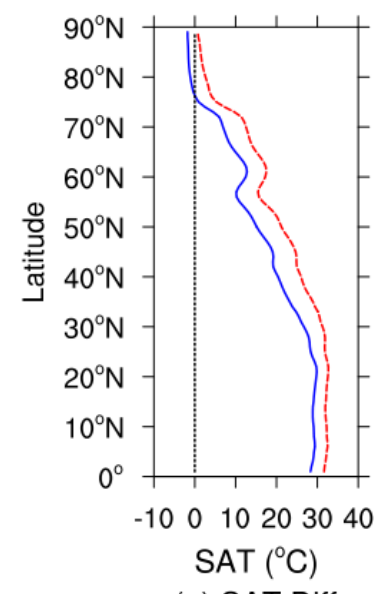

(e) SAT Diff

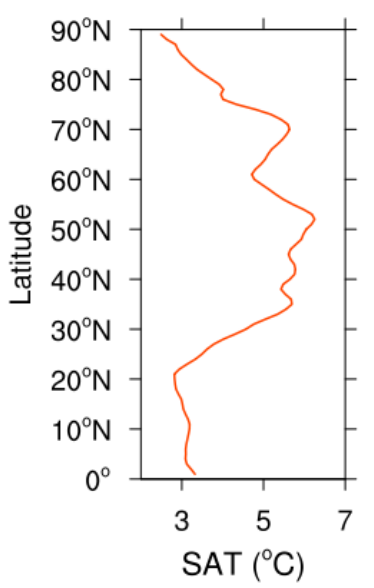

(b) Z500

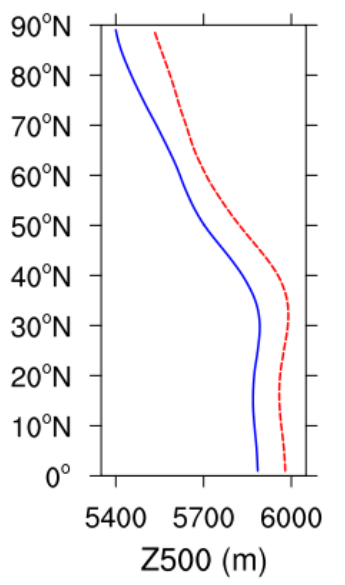

(f) Z500 Diff

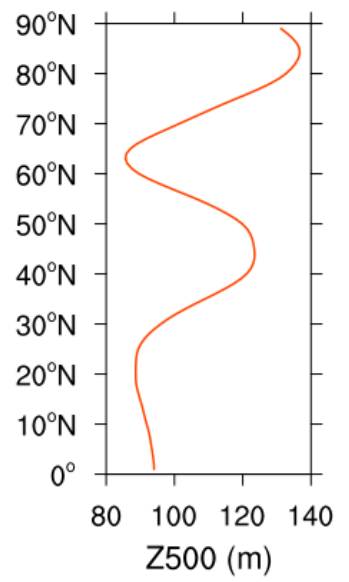

(c) U500



(g) U500 Diff

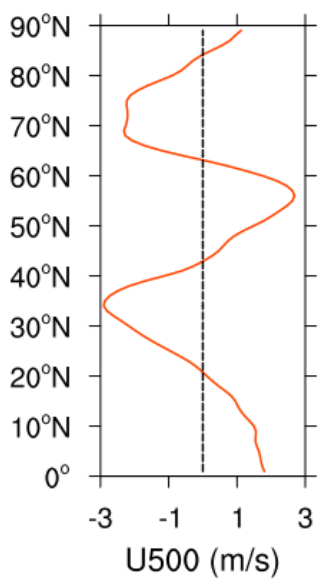

(d) V850

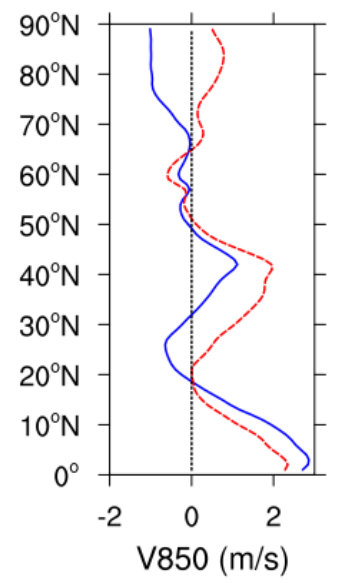

(h) V850 Diff

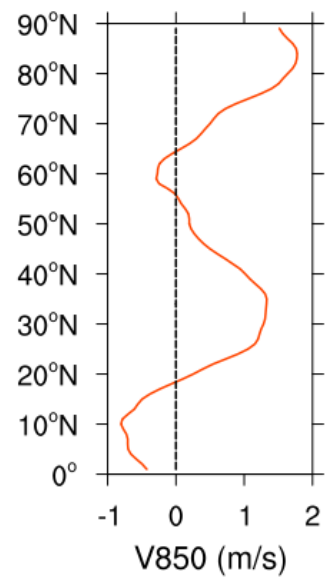

Figure 9. Averages of the different variables for each latitude: $(\mathbf{a})$ SAT $\left({ }^{\circ} \mathrm{C}\right),(\mathbf{b}) \mathrm{Z} 500(\mathrm{~m}),(\mathbf{c}) \mathrm{U} 500(\mathrm{~m} / \mathrm{s}),(\mathbf{d}) \mathrm{V} 850$ (m/s). Future changes for $(\mathbf{e}) \operatorname{SAT}\left({ }^{\circ} \mathrm{C}\right),(\mathbf{f}) \mathrm{Z} 500(\mathrm{~m}),(\mathrm{g}) \mathrm{U} 500(\mathrm{~m} / \mathrm{s}),(\mathbf{h})$ V850 (m/s).

\subsection{2. $35^{\circ} \mathrm{N}-50^{\circ} \mathrm{N}$}

In this interval, the increases in SAT and Z500 are the most obvious. U500 is still westerly but will decrease significantly in most areas. At the same time, V850 is southerly and will have a certain degree of increase. These conditions are beneficial to the rise of SAT.

\subsection{3. $20^{\circ} \mathrm{N}-35^{\circ} \mathrm{N}$}

In this interval, the increases in SAT and Z500 have a certain gradient. The increases are greater at higher latitudes. East winds increase and have a certain gradient. The easterly winds increase with increasing latitude. In addition, the weak north winds will evolve into weak south winds.

\subsection{4. $0^{\circ} \mathrm{N}-20^{\circ} \mathrm{N}$}

In this interval, the increases in SAT and Z500 are small. The increase in westerly winds and decrease in southerly winds will be unfavorable to the increase in SAT.

\subsection{Distribution Regularities in Different Latitudes for Each Climate Variable}

At the end of the 20th century, the $5950 \mathrm{~m}$ (low latitude), $5850 \mathrm{~m}$ (middle latitude), and $5450 \mathrm{~m}$ (high latitude) isohypses were representative of the Z500 isohypses. At the end of the 21st century, they will be replaced with $6050 \mathrm{~m}, 5900 \mathrm{~m}$, and $5500 \mathrm{~m}$. The frequencies of CSIN changes are shown in Figure 10. 
(a) Low latitudes

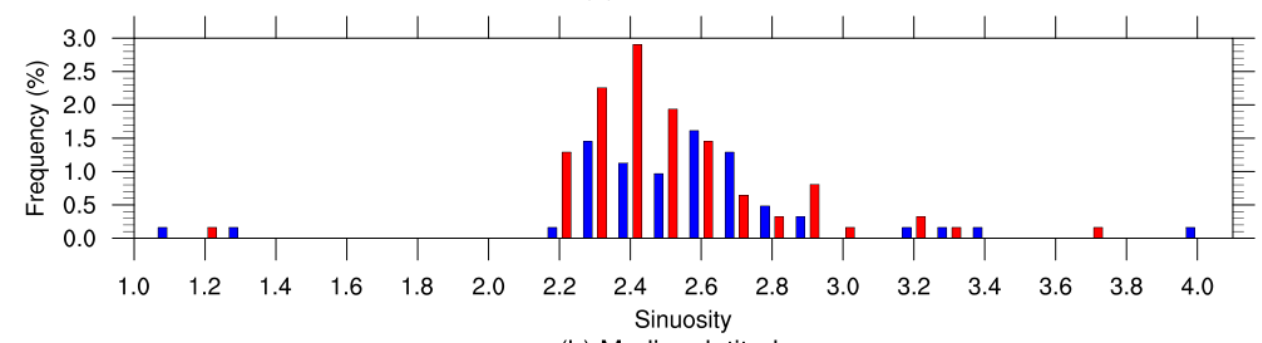

(b) Medium latitudes

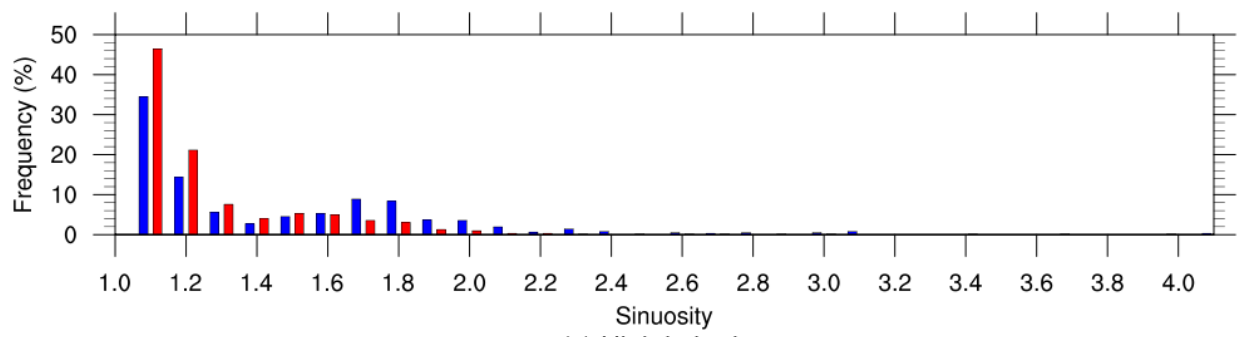

(c) High latitudes

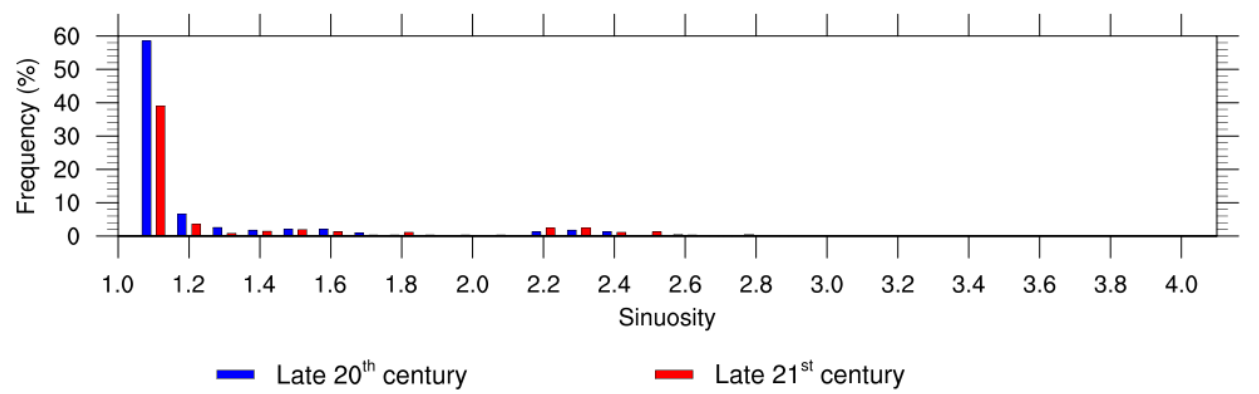

Figure 10. CSIN changes at different latitudes at the late 21st century: (a) low latitudes, (b) medium latitudes, (c) high latitudes.

At low latitudes, the frequencies of CSIN up to 2.5 show a significant increase, indicating that the isohypses near low latitudes will become more curved with the exception of 2.6-2.8. This means that the accumulation of heat in the small domain becomes easier. In the mid latitudes, the frequencies of CSIN in the 1.1-1.3 interval will be significantly higher, and the frequencies of CSIN in the 1.7-2.0 interval will decrease obviously, indicating that the middle latitude isohypses will become straighter. With the westerly wind becoming larger, the cold air coming from high latitudes will be blocked, and the accumulation of heat in the small domain will be easier. In the high latitudes, the frequencies of CSIN in the 1.1-1.3 interval will clearly decrease, indicating that the Arctic Oscillation will be more intense and that the Arctic amplification effect will be strengthened. However, the effect of the Arctic Oscillation on the SAT of the small region is limited due to the strengthening of the barrier effect of the westerly belt.

\section{Summary and Discussion}

Using three sinuosity metrics, circulation waviness (expressed as sinuosity) was examined by linking it to HTEs, and their future changes were projected. The main conclusions are summarized as follows:

- The exceptional circulation states can be quantified by ASIN. The HTEs can more easily appear when ASIN is at its peak.

- Influences of SINs at different latitudes on the SAT of southeastern China differ. The SAT of southeastern China becomes higher with greater ASIN. ASIN in the mid latitudes is the equivalent of a barrier here, which can effectively prevent the cold northern air from going south. 
- Projections of future average SAT indicate a significant increase and a northwestsoutheast gradient warming in August over southeastern China.

- In the bigger picture, SAT changes in southeastern China can be explained by the CSIN of Z500 isohypses at different latitudes. At the end of the 21st century, Z500 isohypses at different latitudes will obviously have a poleward shift. Moreover, the frequencies of large (small) CSIN at low (mid) latitudes increased.

The results can be used as a basis for understanding a broad scale of relationship, such as circulation waviness and its influence on HTEs. Moreover, it can be both useful and insightful to better understand the physical mechanisms behind this phenomenon.

In Vavrus et al. [24], it was demonstrated that changes in SIN are inversely correlated with changes in U500 at nearly all latitudes, both in the projections and as observed during recent decades. Similarly, in this study, we find the same rules on the region from the Equator to the North Pole and covering southeastern China. The occurrence of HTE has a strong regularity. For example, it often occurs when U500 is smaller or V850 is bigger. This indicates that the weaker and wavier flow promotes drying and enhanced heating, thus favoring more intense summer weather [24].

Our study generally supports previous studies' findings that anticyclones with bigger ASIN values (higher meandering) are more likely to cause high temperature weather [23,24]. However, in principle a situation that features a blocking low would also give a high ASIN index, while the circulation pattern is reversed.

Moreover, some of our results differ from those of previous studies $[23,24]$ for the regional differences. When we focus our attention on southeastern China and study the impacts of ASINs in different latitudes on this region, ASINs in different latitudes have different effects on the SAT in southeastern China. A reason for this could be the meridional distribution and movement of pressure belts and wind belts.

A comparison of our results with those of previous studies $[23,24]$ indicates that the climate conditions are more favorable for generating HTEs in the future by calculating the frequency variations of the different magnitudes of the climate variables, although the average states fail to directly reveal the performance of future climate changes on the weather scale. These results also suggest that based on analysis carried out for the sinuosity of isohypses at different latitudes, the effect on HTEs in southeastern China can produce different results. Considering the projected northward shift of the subtropical jet and the expansion of the Hadley cell, the impacts will be more complicated in the future. In addition, our work is more focused on a local scale because local climate change is more complicated. However, further analyses are required to better understand those changes.

Global warming will be a great challenge for us because extreme weather and climate events occur more frequently in the presence of global warming. The relationship between regional circulation modes and temperature changes is very complicated. Changes in SAT and HTE may be influenced by foehn circulation $[43,44]$, in addition to anticyclonic anomalies. The causes of these events need to be further investigated in depth in the future so as to provide more references for the prediction of persistent high temperature events. In addition, the method presented in this paper can be extended to other high-impact phenomena, such as extreme precipitation and drought. The following work is planned for the future, such as improved modeling of rainfall fields under changing climates [45,46], waiting time between two consecutive rainfall events, and a reasonable link by increasing or not increasing the likelihood of heavy and localized rainfall events [47].

Author Contributions: Conceptualization, Y.W.; project administration, Y.W.; supervision, X.S.; validation, F.W.; writing-original draft, X.S.; writing-review and editing, Y.W. All authors have read and agreed to the published version of the manuscript.

Funding: This research was funded by the China Postdoctoral Science Foundation, Grant No. 2018M632334.

Institutional Review Board Statement: Not applicable. 
Informed Consent Statement: Not applicable.

Data Availability Statement: NCEP_Reanalysis 2 data provided by the NOAA/OAR/ESRL PSL, Boulder, Colorado, USA, from their Web site at https://psl.noaa.gov/data/gridded/data.ncep. reanalysis $2 . \mathrm{html} /$, accessed on 1 July 2021. The $1^{\circ} \times 1^{\circ}$ version of the high-resolution gridded daily dataset CN05 (1961-2005), which was generated by Xu et al. based on the 751 gauge stations in China, was employed. The outputs of CMIP5 models were derived from the PCMDI (at http: / / pcmdi9.1lnl.gov/ esgf-web-fe/, accessed on 1 July 2021).

Acknowledgments: This work was supported by the China Postdoctoral Science Foundation (Grant No. 2018M632334) and the Radar Imaging and Microwave Photonic Technology Key Laboratory of the Ministry of Education Grant. The NCEP/NCAR data were provided by the NOAA-CIRES Climate Diagnostics Center, Boulder, Colorado, USA (http:/ / www.cdc.noaa.gov: accessed on 10 August 2019). A set of gridded daily temperature data was provided by $\mathrm{Xu}$ et al. (referred to as CN05).

Conflicts of Interest: The authors declare no conflict of interest. The funders had no role in the design of the study; in the collection, analyses, or interpretation of data; in the writing of the manuscript; or in the decision to publish the results.

\section{References}

1. Meehl, G.A.; Tebaldi, C. More intense, more frequent, and longer lasting heat waves in the 21st century. Science 2004, 305, 994-997. [CrossRef]

2. Perkins, S.E.; Alexander, L.V.; Nairn, J.R. Increasing frequency, intensity and duration of observed global heatwaves and warm spells. Geophys. Res. Lett. 2012, 39, L20714. [CrossRef]

3. Wang, H.; Sun, J.; Chen, H.; Zhu, Y.; Zhang, Y.; Jiang, D.; Yang, S. Extreme climate in China: Facts, simulation and projection. Meteorol. Z. 2012, 21, 279-304. [CrossRef]

4. Trenberth, K.E.; Dai, A.; van der Schrier, G.; Jones, P.D.; Barichivich, J.; Briffa, K.R.; Sheffield, J. Global warming and changes in drought. Nat. Clim. Chang. 2014, 4, 17-22. [CrossRef]

5. Wang, H.; Chen, H. Understanding the recent trend of haze pollution in eastern China: Roles of climate change. Atmos. Chem. Phys. Discuss. 2016, 1-18. [CrossRef]

6. Christensen, J.H.; Hewitson, B.; Busuioc, A.; Chen, A.; Gao, X.; Held, I.; Jones, R.; Kolli, R.K.; Kwon, W.T.; Laprise, R.; et al. Regional climate projections. In Climate Change 2007: The Physical Science Basis; Solomon, S., Ed.; Cambridge University Press: Cambridgeshire, UK, 2007; pp. 847-940.

7. Christensen, J.H. Coauthors. Climate phenomena and their relevance for future regional climate change. In Climate Change 2013: The Physical Science Basis; Stocker, T.F., Ed.; Cambridge University Press: Cambridgeshire, UK, 2013; pp. 1217-1308. [CrossRef]

8. Min, S.K.; Kim, Y.H.; Kim, M.K.; Park, C. Assessing human contribution to the summer 2013 Korean heat wave in Explaining Extreme Events of 2013 from a Climate Perspective. Bull. Amer. Meteorol. Soc. 2014, 95, S48-S51.

9. Min, S.K.; Son, S.W.; Seo, K.H.; Kug, J.S.; An, S.I.; Choi, Y.S.; Lee, M.I. Changes in weather and climate extremes over Korea and possible causes: A review. Asia-Pac. J. Atmos. Sci. 2015, 51, 103-121. [CrossRef]

10. Wei, J.; Yang, H.; Sun, S.Q. Relationship between the anomaly longitudinal position of subtropical high in the western Pacific and severe hot weather in North China in summer. Acta. Meteorol. Sin. 2004, 62, 308-316. (In Chinese)

11. Maheras, P.; Flocas, H.; Tolika, K.; Anagnostopoulou, C.; Vafiadis, M. Circulation types and extreme temperature changes in Greece. Clim. Res. 2006, 30, 161-174. [CrossRef]

12. Gershunov, A.; Cayan, D.R.; Iacobellis, S.F. The great 2006 heat wave over California and Nevada: Signal of an increasing trend. J. Clim. 2009, 22, 6181-6203. [CrossRef]

13. Sun, J.H.; Chen, H.; Zhao, S.W.; Zeng, Q.C.; Xie, Z.; Cui, J.L.; Liu, H.T. A study on the severe hot weather in Beijing and North China. Part II. Simulation and analysis. Clim. Environ. Res. 1999, 4, 334-345. (In Chinese)

14. Black, E.; Blackburn, M.; Harrison, G.; Hoskins, B.; Methven, J. Factors contributing to the summer 2003 European heatwave. Weather 2004, 59, 217-223. [CrossRef]

15. Zhang, M.; Fu, G.; Guo, J. Diagnostical analysis of an extreme high-temperature weather event in North China on 15 July, 2002. J. Ocean. Univ. China. 2005, 35, 183-188. (In Chinese)

16. Zaitchik, B.F.; Macalady, A.K.; Bonneau, L.R.; Smith, R.B. Europe's 2003 heat wave: A satellite view of impacts and landatmosphere feedbacks. Int. J. Climatol. 2006, 26, 743-769. [CrossRef]

17. Zhang, Y.; Zhang, S. Causation analysis on a largescale continuous high temperature process occurring in North China plain. Meteorol. Mon. 2010, 36, 8-13. (In Chinese)

18. Ziv, B.; Saaroni, H.; Alpert, P. The factors governing the summer regime of the eastern Mediterranean. Int. J. Climatol. 2004, 24, 1859-1871. [CrossRef]

19. Harpaz, T.; Ziv, B.; Saaroni, H.; Beja, E. Extreme summer temperatures in the east Mediterranean-Dynamical analysis. Int. J. Climatol. 2014, 34, 849-862. [CrossRef] 
20. Sun, J.; Wang, H. Regional Difference of Summer Air Temperature Anomalies in Northeast China and Its Relationship to Atmospheric General Circulation and Sea Surface Temperature. Chin. J. Geophys. CH. 2006, 49, 588-598. [CrossRef]

21. Sun, J.; Wang, H.; Yuan, W. Decadal variations of the relationship between the summer North Atlantic Oscillation and middle East Asian air temperature. J. Geophys. Res. Atmos. 2008, 113, D15107. [CrossRef]

22. Sun, J.; Wang, H.; Wei, A.Y. Decadal Variability of the Extreme Hot Event in China and Its Association with Atmospheric Circulations. Clim. Environ. Res. 2011, 16, 199-208. (In Chinese)

23. Cattiaux, J.; Peings, Y.; Saint-Martin, D.; Trou-Kechout, N.; Vavrus, S.J. Sinuosity of midlatitude atmospheric flow in a warming world. Geophys. Res. Lett. 2016, 43, 8259-8268. [CrossRef]

24. Vavrus, S.J.; Wang, F.; Martin, J.E. Changes in North American Atmospheric Circulation and Extreme Weather: Influence of Arctic Amplification and Northern Hemisphere Snow Cover. J. Clim. 2017, 30, 4317-4333. [CrossRef]

25. Peings, Y.; Cattiaux, J.; Vavrus, S.; Magnusdottir, G. Late twenty-first-century changes in the midlatitude atmospheric circulation in the CESM large ensemble. J. Clim. 2017, 30, 5943-5960. [CrossRef]

26. Di Capua, G.; Coumou, D. Changes in meandering of the Northern Hemisphere circulation. Environ. Res. Lett. 2016, 11, 094028. [CrossRef]

27. Seneviratne, S.I. Coauthors. Changes in climate extremes and their impacts on the natural physical environment. In Managing the Risks of Extreme Events and Disasters to Advance Climate Change Adaptation; Field, C.B., Ed.; Cambridge University Press: Cambridgeshire, UK, 2012; pp. 109-230.

28. Lucas, C.; Timbal, B.; Nguyen, H. The expanding tropics: A critical assessment of the observational and modeling studies. WIREs. Clim. Chang. 2013, 5, 89-112. [CrossRef]

29. Kanamitsu, M.; Ebisuzaki, W.; Woollen, J. NCEP-DOE AMIP-II Reanalysis (R-2). Bull. Amer. Meteorol. Soc. 2002, 83, 1631-1643. [CrossRef]

30. Xu, Y.; Gao, X.; Shen, Y.; Xu, C.; Shi, Y.; Giorgi, F. A Daily Temperature Dataset over China and Its Application in Validating a RCM Simulation. Adv. Atmos. Sci. 2009, 26, 763-772. [CrossRef]

31. Taylor, K.E.; Stouffer, R.J.; Meehl, G.A. An overview of CMIP5 and the experiment design. Bull. Amer. Meteorol. Soc. 2012, 93, 485-498. [CrossRef]

32. Zhao, S.; He, W. Performance evaluation of Chinese air temperature simulated by Beijing Climate Center Climate System Model on the basis of the long-range correlation. Acta. Phys. Sin. 2014, 63, 209201. (In Chinese)

33. Zhao, S.; He, W. Performance evaluation of the simulated daily average temperature series in four seasons in China by Beijing Climate System Model. Acta. Phys. Sin. 2015, 64, 049201. (In Chinese)

34. Tian, Y.Z.; Chen, S.P.; Yue, T.X.; Zhu, L.F.; Wang, Y.A.; Fan, Z.M.; Ma, S.N. Simulation of Chinese population density based on land use. Acta. Geogr. Sin. 2004, 59, 283-292. (In Chinese)

35. Ge, M.L.; Feng, Z.M. Population distribution of China based on GIS: Classification of population densities and curve of population gravity centers. Acta. Geogr. Sin. 2009, 64, 202-210. (In Chinese)

36. Wang, Z.F.; Chen, P. Unbalanced economic development and coordinated development of eastern and western China. J. Jishou. Univ. 2010, 31, 111-115.

37. Chen, R.; Lu, R. Comparisons of the Circulation Anomalies Associated with Extreme Heat in Different Regions of Eastern China. J. Clim. 2015, 28, 5830-5844. [CrossRef]

38. Zhang, Q.; Chen, L. Variations of dryness and wetness in China during 1951-1980. Sci. Atmos. Sin. 1991, 15, 72-81. (In Chinese)

39. Wei, K.; Chen, W. Climatology and trend of high temperature extremes across China in summer. Atmos. Oceanic. Sci. Lett. 2009, 2, 153-158.

40. Zheng, J.; Yin, Y.; Li, B. Scheme of climate regionalization in China. Acta. Geogr. Sin. 2010, 65, 3-13. (In Chinese)

41. Barnes, E.A. Revisiting the evidence linking Arctic amplification to extreme weather in midlatitudes. Geophys. Res. Lett. 2013, 40, 4734-4739. [CrossRef]

42. Quante, M.; Colijn, F.; Sterl, A. North Sea Region Climate Change Assessment; Springer International Publishing: Berlin, Germany, 2016.

43. Oard, M.J. A method for predicting chinook winds east of the Montana Rockies. Weather Forecast 1993, 8, 166-180. [CrossRef]

44. Mercer, A.E.; Richman, M.B.; Bluestein, H.B. Statistical modeling of downslope windstorms in Boulder, Colorado. Weather Forecast 2008, 23, 1176-1194. [CrossRef]

45. Manton, M.J. Trends in extreme daily rainfall and temperature in Southeast Asia and the South Pacific: 1961-1998. Int. J. Climatol. 2001, 21, 269-284. [CrossRef]

46. Sheikh, M.M.; Manzoor, N.; Ashraf, J.; Adnan, M.; Collins, D.; Hameed, S.; Manton, M.J.; Ahmed, A.U.; Baidya, S.K.; Borgaonkar, H.P. Trends in extreme daily rainfall and temperature indices over South Asia. Int. J. Climatol. 2015, 35, 1625-1637. [CrossRef]

47. De Luca, D.L.; Petroselli, A.; Galasso, L. A Transient Stochastic Rainfall Generator for Climate Changes Analysis at Hydrological Scales in Central Italy. Atmosphere 2020, 11, 1292. [CrossRef] 